\title{
A Demometric Analysis of the Croatian Population
}

\author{
Ana Štambuk \\ School of Economics of the University of Rijeka, Croatia
}

\begin{abstract}
In Croatia as in other European countries we experience a decrease of fertility and a demographic ageing of the population. In almost all the countries the level of fertility is below the replacement level. The decrease of the fertility and the increase of life expectancy leads to a larger proportion of the elderly population and to a decrease of the potential working contingent, which influences the entire economic development. A systematic analysis of the population is therefore essential. To analyze the population, as precise as possible, we apply demometric methods. Thus, the fertility, the stable population model, and the hidden population momentum are analyzed.
\end{abstract}

Besides usual demographic measurements we also calculate the BongaartsFeeney quantum and tempo of fertility and the Coale-Trussell fertility method. The intrinsic growth rate of a stable population model is also determined. The population momentum describes a possible reason for the changing number of inhabitants. All these demometric methods are also applied on other countries so that the Croatian population can be compared to other populations of European countries.

Zusammenfassung: In Kroatien wie auch in anderen europäischen Ländern gab es eine Abnahme der Fertilität und eine demographische Alterung der Bevölkerung. In fast allen Ländern liegt das Niveau der Fertilität unter dem Replacement Level. Die Abnahme der Fertilität und die Zunahme der Lebenserwartung hat einen wachsenden Anteil der älteren Bevölkerung sowie einer Reduktion des Arbeitskontingentes zur Folge, was wiederum Einfluss auf die gesamte wirtschaftliche Entwicklung hat. Eine systematische Analyse der Bevölkerung ist deshalb äußerst wichtig. Damit die Bevölkerung so genau wie nur möglich analysiert werden konnte, werden demometrische Methoden angewandt. Analysiert wurden hierbei die Fertilität, ein stabiles Bevölkerungsmodell und ein verstecktes Bevölkerungsmoment.

Neben üblichen demographischen Maßen wurde das Bongaarts-Feeney Quantum und das Tempo der Fertilität berechnet, sowie die Coale-Trussell Methode der Fertilität. Auch bestimmt wurde die intrinsische Wachstumsrate in einem stabilen Bevölkerungsmodell. Das Bevölkerungsmoment beschreibt eine potentielle Ursache für ein sich ändernde Anzahl von Einwohnern. All diese demometrische Methoden werden auch auf andere Staaten angewendet so dass die kroatische Bevölkerung mit anderen europäischen Bevölkerungen verglichen werden kann.

Keywords: Demometry, Fertility, Stable Population, Population Momentum. 


\section{Introduction}

Croatia is faced with the problem of natality and a demographic aging of the population. The population of Croatia is continuously decreasing. At the time of acquiring independence in 1991 Croatia had 4.513 million inhabitants, thereafter, the population decreased to 4.443 millions in 2002 (CBS, 2004). According to the UN (2004) evaluation such trend shall continue, and in 2050 Croatia shall have $19 \%$ less inhabitants then in 2000, i.e. a population of 3.587 millions.

The main cause for such a decrease, after demographic transition is decrease in natality rate. The crude birth rate is lower than the mortality rate. The total fertility rate in Croatia in 2002 was 1.34 (Eurostat, 2005), which is below a rate of 2.1, necessary to reach simple reproduction. Such small rates, smaller than 2.1, are already common since 1965 (UN, 2003). Population aging is observed from the participation of population 65 years of age or older throughout many years. In the intercensal period 1991-2001 the fraction of older population increased from $11.8 \%$ to $15.7 \%$ (CBS, 2004). Natality decrease and population aging is not characteristic for Croatia only, but for entire Europe. According to CEC (2004) the only European state in 2002 with a total fertility rate above the level of simple reproduction was Turkey.

The whole world is experiencing a decreasing fertility and an increase of life expectancy. This means that there is more and more older population, especially in European countries. From the economic point of view population aging is becoming an overall problem. As a result of such a trend in population dynamics, the proportion of the working age population is decreasing, while the older population keeps increasing.

In Section 2 we analyze fertility. This analysis was done through fertility rates with application of quantum and tempo fertility analyzes according to the Bongaarts-Feeney method. We also analyze the Coale-Trussell marital fertility. The third section deals with a stable population model and with the intrinsic growth rate. The hidden moment of the population growth is elaborated in Section 4. The fifth section is dedicated to some conclusions. All the calculations are done in Excel.

\section{Analysis of Fertility}

\subsection{Fertility Rates}

Fertility supposes the rate between born children and the number of fertile women. Since only persons in their fertility age participate in the reproduction, as natality parameters, different fertility rates are usually applied since they consider the number of life born children and women in their fertility age. Fertility rates assume general fertility rate, specific, and total fertility rate. The general fertility rate (GFR) represents the relation between live born children and the number of women in fertile age and is calculated as

$$
\mathrm{GFR}=\frac{N}{{ }_{35} P_{f, 15}} 1000,
$$

where $N$ is the number of live births and ${ }_{35} P_{f, 15}$ denotes the size of the female population aged 15 to 49 on June 30th of any given year. The general fertility rate range from $0.005 \%$ 
to 3\% (Rowland, 2003). This is also a crude rate which is explained below, because it includes all the women in their fertility age, irrespectively of the fact weather they have or have not given a birth. Since pregnancy depends on the age of mother, consideration of the fertility rate according certain age group seems to be more appropriate. Such rate is called specific fertility age rate and is computed as

$$
{ }_{n} f_{x}=\frac{{ }_{n} N_{x}}{{ }_{n} P_{f, x}} 1000
$$

where $f_{x}$ denotes the age specific fertility rate of the female population aged $x$ to $x+n$, ${ }_{n} N_{x}$ is the number of live births given by a women aged $x$ to $x+n$, and ${ }_{n} P_{f, x}$ is the size of the female population aged $x$ to $x+n$ calculated on June 30th.

The specific fertility rate is computed for the women population aged $15-49$, while the single rate is usually calculated for five year periods. The specific fertility rate supposes the number of live births given per 1000 females in the appropriate age group. As far as the specific fertility rate is concerned the computation considers the total fertility rate (TFR), obtained by summing the age specific rates for a given time point, i.e.

$$
\mathrm{TFR}=\frac{n \sum_{x=15, n}^{49}{ }_{n} f_{x}}{1000} .
$$

The TFR represents an average number of children born by a woman during her fertile period, given she survived the entire period. This rate is used as an indication for the population reproduction.

Often TFR is used to estimate the fertility growth factor in a population, i.e. whether the childbearing population is replacing itself or not. Thus, TFR $\geq 2.0 \mathrm{bpw}$ indicates that on average couples are producing at least two children to replace themselves. If TFR $>2.0 \mathrm{bpw}$ for a longer time period, the size of the next generation of childbearing age is likely larger than the present one of that age if all other influential parameters affecting the population like death rates or migration remain the same. However, since not all the women survive their fertile period a threshold value of 2.1 is considered in order to ensure at least simple reproduction. Therefore, if TFR $=2.1 \mathrm{bpw}$, then the simple population reproduction is obtained. A TFR $>2.1 \mathrm{bpw}$ indicates an expanded population reproduction, and TFR $<2.1 \mathrm{bpw}$ stands for a decreased population reproduction.

The demographic transition model aims to explain the transformation of countries from having high birth and death rates to low birth and death rates and is based on the change in crude birth rate (CBR) over time expressed per thousand population. The CBR is a value that measures the growth of a population and is called crude because it does not take into account the age or the sex differences among the population. The CBR is determined by taking the number $N$ of childbirths in one year in a certain country, dividing it by $p$, the country's population, and multiplying this number by 1000 , i.e.

$$
\mathrm{CBR}=\frac{N}{p} 1000 .
$$

Croatia has gone through the process of demographic transition. The CBR has been decreasing for many years and sometimes it was even lower than the mortality rate. Especially in the period $1960-2002$ this rate decreased from $1.84 \%$ to $0.9 \%$. 
Because it is only a crude indicator of some fertility movement, we apply instead the TFR as a measure of population reproduction. Way back in the sixties the TFR in Croatia started to decrease below the replacement level. From 1965 to 2002 it reached a level just below the replacement rate. The only European country in 2002 with a TFR above the simple reproduction was Turkey with $2.46 \mathrm{bpw}$. The lowest value was observed in the Czech Republic with 1.18bpw, while for Croatia it was 1.34bpw at that time (CEC, 2004).

\subsection{The Bongaarts-Feeney Method}

The TFR is the most commonly used measure of fertility. However, it may also lead to wrong conclusions, a fact which is well known in demography (Land et al., 2005; Bongaarts, 1999; Yi and Land, 2001).

The fertility contains quantum and tempo components. The quantum component supposes the value of TFR if no changes occur during measuring the TFR. The tempo component represents the deviation due to a change in the mean age of women at birth (Philipov and Kohler, 2001; Akrap et al., 2003; Yi and Land, 2001). When children are born at mothers' later age the TFR decreases. With decreasing women's age at birth the total fertility increases. This phenomenon of underestimation or overestimation of the fertility is called tempo effect (Philipov and Kohler, 2001).

The fact that there is TFR distortion due to a tempo effect is well known since a long time. However, until recently there is a lack of methodology harmonization, which could correct this deficiency. In 1964 Norman Ryder suggested the application of the translation equation for correcting the computation of fertility (Ryder, 1964). However, his method was never accepted. Bongaarts and Feeney (1998) proposed a simple method to eliminate such a tempo effect from the TFR. By the Bongaarts-Feeney method it is possible to obtain an adjusted TFR, say TFR', which is free from any tempo distortion and is only based upon the quantum component. The quantum component is supposed to better indicate how many births a woman shall give on average during her fertile period, assuming that a reproductive behavior continues.

The TFR can be expressed as

$$
\mathrm{TFR}=\sum_{i} \mathrm{TFR}(i)
$$

where $i$ denotes the parity and $\operatorname{TFR}(i)$ is the TFR for the $i$ th parity. TFR $(i)$ refers to the $i$ th parity only. The adjusted TFR is calculated as

$$
\mathrm{TFR}^{\prime}=\sum_{i} \mathrm{TFR}^{\prime}(i)
$$

where TFR' $(i)$ is the adjusted TFR of parity $i$, i.e.

$$
\operatorname{TFR}^{\prime}(i)=\frac{\operatorname{TFR}(i)}{1-r_{i}}
$$

For any given year the change in the mean age of woman giving birth to their $i$ th child is denoted by $r_{i}$. 
Table 1: The fertility quantum and tempo for 1995-2001

\begin{tabular}{cccc}
\hline Years & TFR & Quantum & Tempo \\
\hline 1995 & 1.58 & 1.80 & 0.22 \\
1996 & 1.67 & 1.85 & 0.18 \\
1997 & 1.69 & 1.87 & 0.18 \\
1998 & 1.45 & 1.53 & 0.08 \\
1999 & 1.38 & 1.57 & 0.19 \\
2000 & 1.39 & 1.81 & 0.42 \\
2001 & 1.38 & 1.75 & 0.37 \\
\hline Mean & 1.51 & 1.74 & 0.24 \\
\hline
\end{tabular}

Source: Author's computation based on UN (1999); CBS (1999, 2004); Eurostat (2005)

The Bongaarts-Feeney method proved to be useful when analyzing fertility, especially in cases when the childbearing age is changing. The TFR' represents the fertility quantum, i.e. a fertility free from any tempo effect. A quantum component means a better indication of how many children on average a woman will give birth to during her fertile period, if her reproductive behavior will continue. The method became quite popular in demography and there have already been suggestions to work on the improvement of this method (Philipov and Kohler, 2001).

The fertility in Croatia in the last several years was analyzed by applying the BongaartsFeeney method. Data regarding the number of children according to the parity and to the mother's age are available for the period 1994-2002. Data for 1994 and for 1996-2002 are available from Eurostat. For 1995 see the report UN (1999). Information about the average mother's age are not available. Thus, it is calculated from the number of born children of each parity and the total numbers of women according to the age groups, which are further calculated from specific fertility rates and from the total numbers of childbirths according to mother's age groups (see CBS, 1999, 2004). The TFR is graded from 1 to 5 parities or as unknown. The 5th parity includes also all higher parities. To estimate the corrected TFR of each parity in time $t$, the quantity

$$
r_{i}(t)=\frac{a_{i}(t+1)-a_{i}(t-1)}{2}
$$

is used, where $a_{i}(t)$ denotes the mean age of mothers given birth to their $i$ th child.

The fertility quantum is the sum of quantum of each parity. Due to the nature of this computation it is impossible to determine the quantum and tempo for the first and the last year. Results are shown in Table 1. It is apparent that in the entirely analyzed period 1995-2001 the fertility is smaller compared to the real one. By eliminating the tempo effect the fertility increases, which is the result of the increasing average age of mothers at childbirth. The tempo effect is largest in 2000 and 2001 and smallest in 1998. During the entire period the fertility is on average 0.24 higher, therefore the average fertility is not 1.51 but 1.74. Observed TFR, mean age, and adjusted TFR are illustrated in Figure 1.

It is obvious that in 1995-1998 the change of fertility rate was influenced by both, quantum and tempo effects. In spite of the increase of the average mothers' age at birth, 


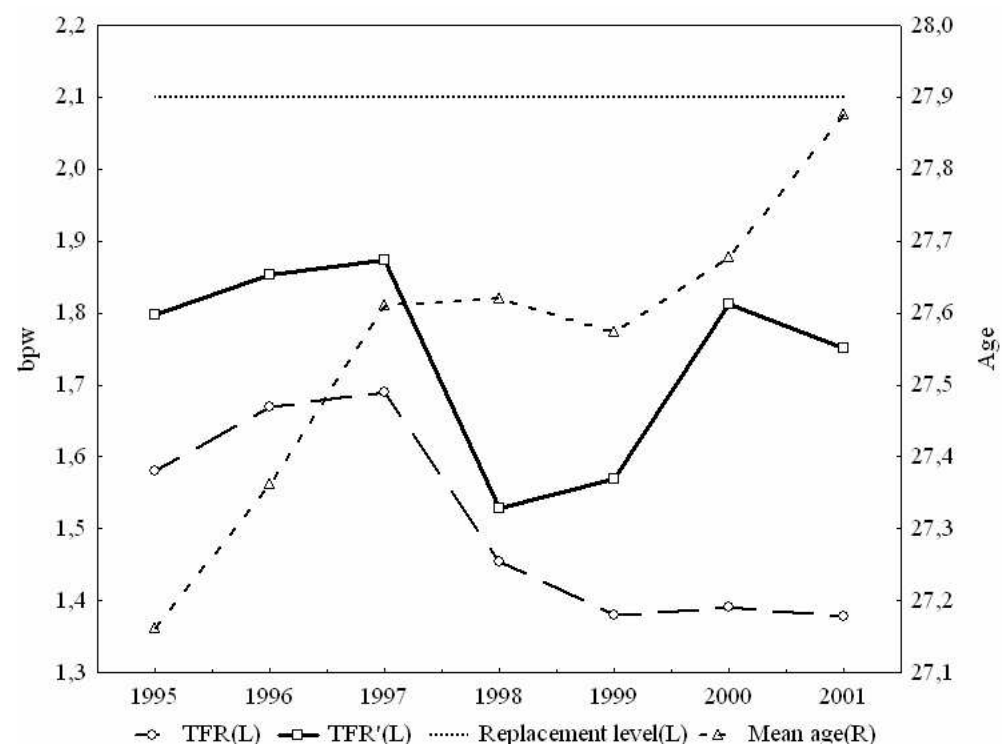

Figure 1: Observed and adjusted TFR and mean age of birth, Croatia, 1995-2001 Source: Author's computation based on UN (1999); CBS (1999, 2004); Eurostat (2005)

also the TFR increased, after which the tempo effect occurred. Due to tempo effect it seems that the fertility keeps decreasing, although the true fertility increases. Another decrease is experienced in 2001, however, it represents the end of the time period.

Partitioning the fertility into fertility quantum indicating the real position of fertility and in tempo distortion, we notice that the situation in Croatia is less bad than expected. However, it is also true that the fertility in anyway is positioned under replacement fertility. The most important conclusion derived from this analysis is that the trend of true fertility dynamics in Croatia is growing and the decrease of TFR is a result of an increasing average age of women at childbirth rather than the decreasing total number of childbirths.

Comparing Croatia with selected European countries, it is obvious that hidden fertility is present in all listed countries (Table 2). Except for Finland, where the fertility is only $0.14 \mathrm{bpw}$, in all other countries it is equal or higher than that of Croatia.

Table 2: Hidden fertility for 1995-2001

\begin{tabular}{lc|lc}
\hline Country & Hidden fertility-tempo & Country & Hidden fertility-tempo \\
\hline Croatia & 0.24 & Iceland & 0.32 \\
Austria & 0.24 & Lithuania & 0.28 \\
Czech Republic & 0.57 & Norway & 0.24 \\
Estonia & 0.48 & Portugal & 0.25 \\
Finland & 0.14 & Slovenia & 0.44 \\
Ireland & 0.24 & Sweden & 0.32 \\
\hline Mean & 0.31 & & \\
\hline
\end{tabular}

Source: Author's computation based on UN (1999); CBS (1999, 2004); Eurostat (2005) 


\subsection{The Coale-Trussell Method}

Coale and Trussell proposed an analysis of fertility, which originates from the assumption that the marital fertility is a combination of the natural fertility and the controlled fertility (Becker and Sidibe, 2001; Malačič, 2003; Land et al., 2005). Fertility without birth control is called natural fertility. In demography this term was introduced by Henry in 1961, and presently we obtain data on natural fertility from the religious sect Hutterits, farmers living in Canada and northern United States. Members of this sect represent a sample of human reproduction capacity (Wertheimer-Baletić, 1999; Rowland, 2003).

The Coale-Trussell method introduces double exponential equation and considers the expression

$$
r(a)=M n(a) \exp (m \nu(a))
$$

where $a$ denotes the age group, $r(a)$ the age specific marital fertility, $M$ is the level of marital fertility, $n(a)$ the natural fertility of age group $a, m$ is the degree of birth control, and $\nu(a)$ the deviation of marital from natural fertility in age group $a$.

The marital fertility $r(a)$ represents the observed marital fertility of a population. The natural age specific fertility $n(a)$ is specified as the fertility of the Hutterits of age group $a$. The estimation of the deviation $\nu(a)$ is based on 43 groups of different marital fertility behaviors. Xie and Pimentel (1992) propose modification of the parameter $\nu(a)$.

The model allows two parameters $M$ and $m$. The factor $M$ represents the level of the curve of the model shown in Figure 1. Factor $m$ is the degree of voluntary birth control, which expresses the increase of deviation with respect to the natural fertility. If $m=0$, only natural fertility is assumed. A value of $m>2$ indicates a very high control degree. The factors $M$ and $m$ are sometimes interpreted as the parameters of the interval and stoppage. In this way $M$ indicates that the fertility depends on natural factors, i.e. lactation, abstinence, and similar. The $m$ parameter corresponds to the effect of contraception, artificial abortion for limitation of birth or full stoppage of birth (Fernando, 2004). In practice the method was very successful in populations without great changes in the degree of fertility control. To determine the parameter values we use

$$
\begin{aligned}
M & =\frac{\operatorname{ASMFR}(20-24)}{n(20-24)} \\
m & =0.2 \sum_{a=25-29}^{45-49} \frac{1}{\nu(a)} \log \frac{\operatorname{ASMFR}(a)}{M n(a)},
\end{aligned}
$$

where $\operatorname{ASFRM}(a)$ denotes the age specific marital fertility rate. In Croatia this marital fertility is based on the number of married women (obtained from the population census from 2001) and on information about their children (available from Eurostat).

Evaluating the Coale-Trussell equation for Croatia in 2001 results in

$$
r(a)=0.56 n(a) \exp (1.94 \nu(a)) .
$$

The parameter $m$ is 1.94 and indicates a high degree of birth limitations. Such a degree of stoppage of fertility is rather high, also compared to other European countries, see Table 3. Out of the 21 analyzed countries the highest reproduction limitation was that of Bulgaria, with a distinctly high coefficient $m=2.63$, while Croatia is ranked on the 
Table 3: Degree of reproduction control according to the Coale-Trussell model for 2001

\begin{tabular}{llll}
\hline Country & $m$ & Country & $m$ \\
\hline Croatia & 1.94 & Lithuania & 1.97 \\
Bulgaria & 2.63 & Luxembourg & 1.28 \\
Czech Republic & 2.04 & The Netherlands & 1.01 \\
Denmark & 1.44 & Norway & 1.12 \\
Finland & 1.14 & Romania & 2.06 \\
France & 1.48 & Switzerland & 1.25 \\
Germany & 1.37 & Slovakia & 2.11 \\
Hungary & 1.75 & Slovenia & 2.11 \\
Ireland & 1.22 & Sweden & 1.22 \\
Island & 0.44 & UK & 1.48 \\
Latvia & 1.81 & & \\
\hline Mean & 1.57 & & \\
\hline
\end{tabular}

Source: Author's computation based on UN (1997); CBS (2004); Eurostat (2005)

seventh position. An indicative fact is that on the top of the scale are countries in transition only, listed in the first eight placements with parameter values $m$ from 1.75 in Hungary up to 2.63 in Bulgaria. Countries not going through transition are positioned lower on the scale, i.e. starting from 0.44 in Island up to 1.48 in UK and in France.

\subsection{The Stable Population Model}

The theory of stable population originated from the twentieth century by use of Alfred Lotka's works. However, the fundamental ideas were taken from Euler's works from the eighteenth century. Assumptions of a stable population model (Schoen, 2002; Preston et al., 2003; Rowland, 2003) is closed towards migrations and constant age specific fertility and mortality rates through a longer period of time. Constant fertility and mortality rates lead to an exponentially increase of the population, so that age structure of the population becomes stable.

The model of stable population has the characteristic of ergodicity, or the system is independent of initial conditions. If two populations have different age structure but the same age specific vital statistical rates, their structures should become similar over time. For each combination of vital rates there exists a stable population if those rates would be continuously achieved. When the rates are not constant, then for each combination we can determine a stable equivalent population. The growth rate of a stable model represents an intrinsic growth rate, which is the result of the specific age mortality and fertility rates analyzed in that year.

The model belongs to the Malthusian theory of population and has an exponential growth rate. Its characteristic equation is

$$
1=\int_{\alpha}^{\beta} \exp (-r x) p(x) f(x) d x
$$

where $\alpha$ and $\beta$ denote the limits of the fertile period, $p(x)$ is the probability of surviving up to age $x, f(x)$ is the age specific fertility rate, and $r$ is the intrinsic growth rate. This 
equation shows that a single birth is the result of the fertility rate $f(x)$ applied on survived persons born earlier, $\exp (-r x)$, where the number of born children increases according to the exponential rate $r$.

The intrinsic growth rate is calculated from the equation above applying different methods. Here we use the Coale equation with three iterations in order to calculate the intrinsic rate of growth.

$$
\begin{aligned}
r_{0} & =\frac{\log \mathrm{NRR}}{27}=\frac{\log \left(\sum_{a=15 ; 5}^{45}{ }_{5} L_{a 5} m_{a}\right)}{27} \\
r_{n+1} & =r_{n}+\frac{y\left(r_{n}\right)-1}{27}, \quad y\left(r_{n}\right)=\sum_{a=15 ; 5}^{45} \exp \left(-r_{n}(a+2.5)\right)_{5} L_{a 5} m_{a},
\end{aligned}
$$

where $r_{n}$ denotes the $n$th iteration of $r,{ }_{5} L_{a}$ is the number of person-years lived between ages $a$ and $a+5$ from female period life table, ${ }_{5} m_{a}$ is the rate of bearing female children between ages $a$ and $a+5$, and NRR the net reproduction rate. Also the mean generation volume can be computed by the intrinsic rate.

The intrinsic growth rate is connected with the net reproduction rate. NRR represents an average number of daughters, which would be born by a woman when fertility and mortality would remain unchanged. NRR should be $1 \mathrm{bpw}$ in order to have the female population regenerated by next generations. If NRR $>1$, then $r>0$, and the total size of the population increases. If NRR $<1$, then $r<0$, and the size of the population decreases. In case of NRR $=1, r=0$ and the total number of inhabitants does not change. We come to a stationary population model as a special model of the stable population.

Applying the stable population model we can predict future populations. We can also use this model to predict some part of the history, and the model is used even in cases of incomplete population data. The intrinsic growth rates are analyzed for Croatia as for other European countries for the period 1985-2000. The intrinsic growth rate of the Croatian population is negative throughout the entire period. Negative values are common for almost entire Europe. Dynamics of intrinsic growth rates are graphically compared in Figure 2. Reviewing these dynamics, we observe a higher decrease at the beginning of the war in 1991 and an increase at the end of the war in 1995. Although at the beginning the rate in Croatia was not high compared to other countries, Croatia is in better position because its rate is stable and its decrease is lower.

\section{The Population Momentum}

A population with neutral intrinsic rate becomes stationary only in the long run. When the fertility is on a replacement level, mortality is constant, and when there is no migration, then another possible reason for an increase or decrease of the population still remains the population structure. Different sizes of the younger and older population cohort represent such a possible reason for a changing population size, labeled as population momentum (Preston et al., 2003; Schoen, 2002; Fernando, 2004).

The population momentum is calculated as the ratio of a future stationary population and the initial size of this population. If the number of inhabitants younger than 30 years 


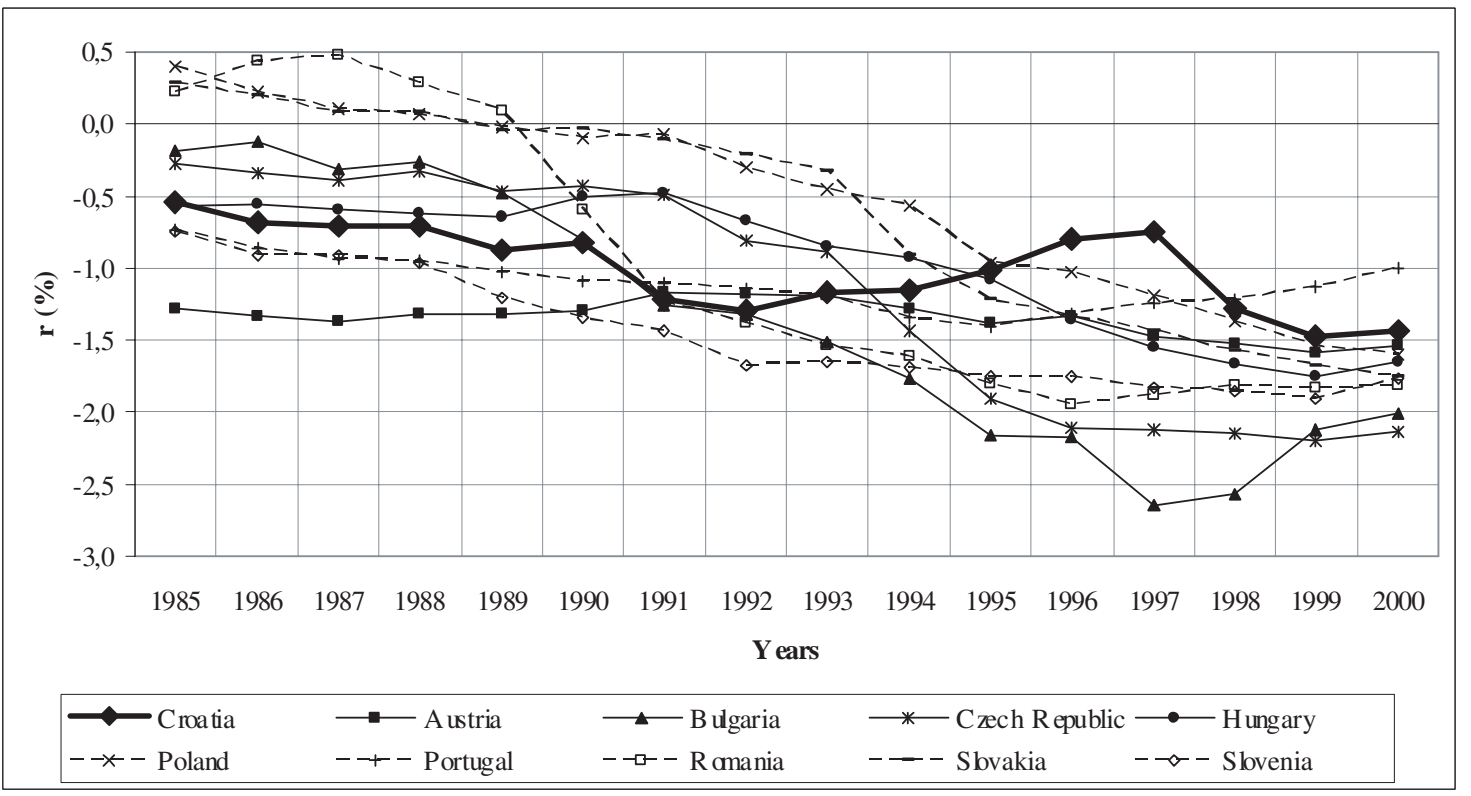

Figure 2: Dynamics of intrinsic growth rates of inhabitants for 1985-2000 Source: Author's computation based on UN (2005)

(which is approximately one generation) is basically constant, then the effect of the population momentum on an increase of inhabitants affects those over 30, and especially those over 60 . The momentum is represented by

$$
M=\int_{0}^{\beta} \frac{c(a)}{c_{S}(a)} \int_{a}^{\beta} p(y) m^{*}(y) d y
$$

where $c(a)$ denotes the proportionate age distribution of the population at the time when replacement-level fertility is imposed, $c_{S}(a)$ is the proportionate age distribution of the stationary population that will eventually emerge, $p(a)$ is the survival function, and $m^{*}$ the replacement-level age specific maternity rates. A momentum larger than 1 indicates younger age structure. In developed countries it usually lies between 1.5 and 1.7 (Schoen, 2002), which explains a population increase even in countries with reduced fertility.

The momentum is estimated by

$$
M=\frac{N_{S}^{F}+N_{S}^{M}}{N^{F}+N^{M}}
$$

where $N_{S}^{F}\left(N_{S}^{M}\right)$ is the number of females (males) in the ultimate population and $N^{F}$ $\left(N^{M}\right)$ the total number of females (males) in this population. Furthermore, we use

$$
\begin{aligned}
& N_{S}^{F}=B_{S}^{F} \cdot e_{0}^{\circ F} \\
& M_{S}^{F}=B_{S}^{F} \cdot \mathrm{SRB} \cdot e_{0}^{\circ M},
\end{aligned}
$$

where $e_{0}^{\circ F}$ and $e_{0}^{\circ M}$ is the female and male life expectancy at birth, $B_{S}^{F}$ denotes the number of births of females in the stationary population, and SRB is the sex ratio at birth. 
Moreover,

$$
\begin{aligned}
B_{S}^{F} & =\sum_{a=0}^{45} \frac{{ }_{5} N_{a}^{F}}{{ }_{5} L_{a}^{F} / 5} \cdot{ }_{5} w_{a} \\
{ }_{5} w_{a} & =\left(\frac{{ }_{5} L_{a}^{F}}{2} \cdot{ }_{5} m_{a}^{*}+\sum_{y=a+5}^{45}{ }_{5} L_{y}^{F} \cdot{ }_{5} m_{a}^{*}\right) / A^{*}
\end{aligned}
$$

where $A^{*}$ is the mean age at birth in the stationary population, ${ }_{5} L_{a}^{F}$ denotes person-years lived between ages $a$ and $a+5$ in the actual female life table with a radix of unity, ${ }_{5} N_{a}^{F}$ is the number of women aged $a$ to $a+5$ in the actual population, and ${ }_{5} m_{a}^{*}$ denotes the replacement-level age specific maternity rates. Finally, the mean age at birth in the stationary population is

$$
A^{*}=\sum_{15}^{45}(a+2.5) \cdot{ }_{5} m_{a}^{*} \cdot{ }_{5} L_{a}^{F}
$$

and the replacement-level age specific maternity rates are

$$
\begin{array}{r}
{ }_{5} m_{a}^{*}=\frac{{ }_{5} m_{a}}{\mathrm{NRR}} \\
\mathrm{NRR}=\sum_{a=15}^{45}{ }_{5} m_{a 5} L_{a}^{F} .
\end{array}
$$

The dynamics of the population momentum in Croatia is compared with other European countries in Figure 3. At the beginning of the reviewed period the population momentum in the majority of the countries was greater than 1. Actually, the population momentum in Croatia was amongst the lowest ones. It appears that in all countries the momentum has a tendency to decrease during this period.

The momentum in Croatia finally reaches the value 1.003. This indicates that we can hardly expect a population increase resulting from the population structure. In Slovakia and in Poland the values are larger than 1, indicating a younger age structure, which to a certain extent enables the possibility of an increase in population without an increase in fertility. In Romania the value is about the same as the value in Croatia and can hardly lead to a population increase. In all the other countries the population momentum is below 1. Croatia does not have high values of the momentum but the dynamics is more balanced and is kept at the same level at the end of the observed period.

\section{Conclusion}

The long term CBR in Croatia is decreasing and sometimes even lower than the mortality rate. Way back in the sixties the TFR started to decrease below the replacement level. However, a decrease of fertility is characteristic for entire Europe and not only for Croatia.

By the Bongaarts-Feeney method fertility is partitioned into fertility quantum and tempo distortion. In the period 1995-2001 the fertility in Croatia is lower than the actual fertility. Hidden fertility is on average 0.24 children per female. Comparing Croatia with other European countries we conclude that in all these populations the actual fertility 


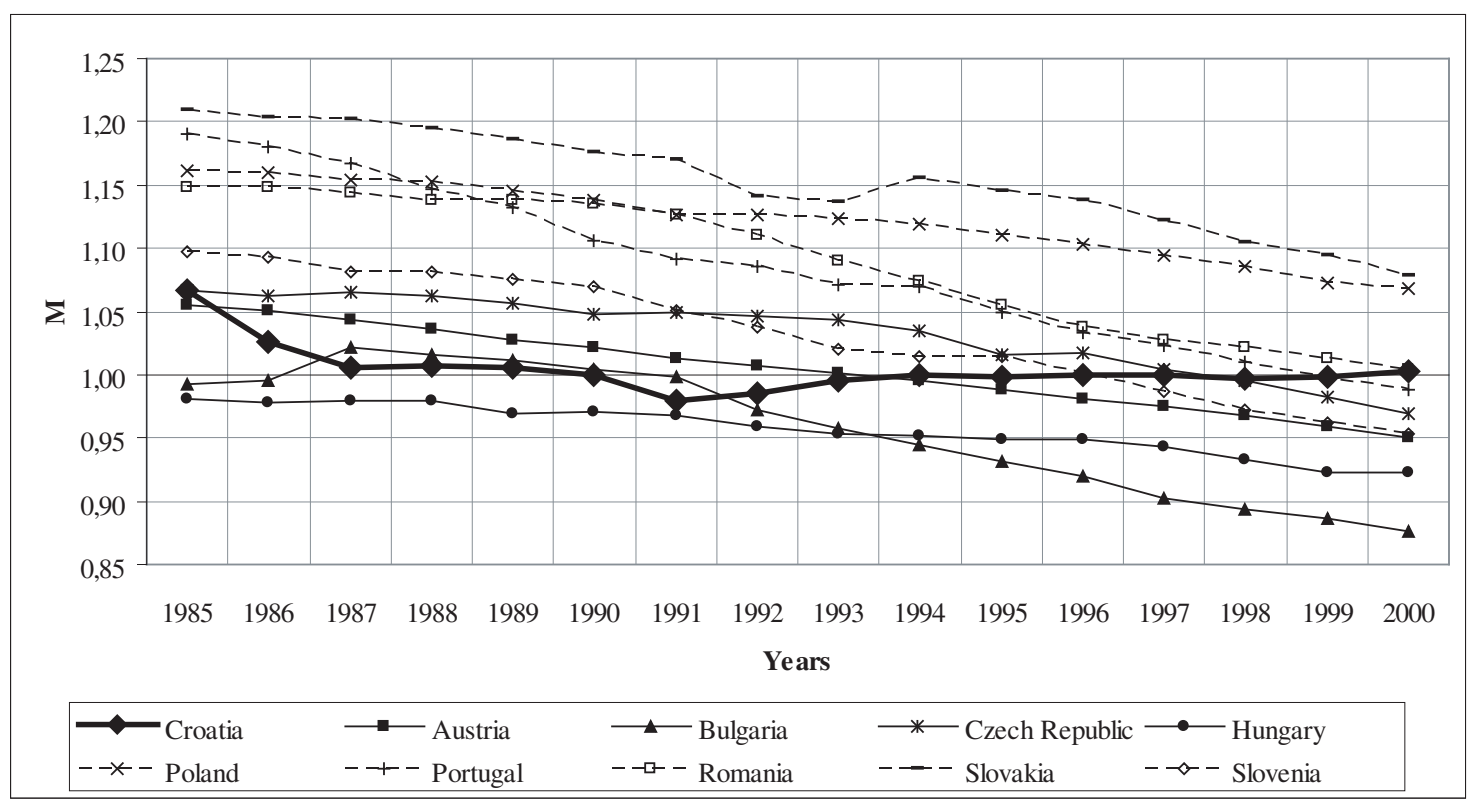

Figure 3: Dynamics of population momentum in the period for 1985-2000 Source: Author's computation based on UN (2005)

increases when removing the tempo effect. The hidden fertility ranges from 0.14 to 0.57 births per woman. The Bongaarts-Feneey method indicates that the actual fertility trend in Croatia is increasing and that the decrease of TFR is the result of an increase in the mean age of females at childbirth rather than a decrease of the total number of born children.

When analyzing the marital fertility by applying the Coale-Trussell method we obtain the degree of the marital reproduction control, which implies a high degree of reproduction limitation. Compared with other European countries, there is really a high degree of slow down of fertility in Croatia, and at the top of the scale are all the countries which are in transition.

The intrinsic growth rate of a stable model is negative throughout the entire analyzed period from 1985 to 2000. Negative values of the intrinsic growth rate are characteristic for almost entire Europe. Although the intrinsic growth rate in Croatia was negative at the beginning of the analysis and lower than in most other European countries, Croatia is in a better position because the dynamics of the rate are more uniformed and the drop rate is lower.

The population momentum indicates that in Croatia it is hard to expect an increase of the population which would be the result of the population structure. As also in other countries, from 1985 to 2000 the population momentum has the tendency of decrease. However, compared with other countries the dynamics of the population momentum is balanced and is kept on a stable level till the end.

Standard demographic measures indicate that the fertility in Croatia is lower with a tendency of decrease. Certain demometric methods, like for example Bongaarts-Feeney and the dynamics of the population momentum, and to some degree even the dynamics of the intrinsic growth rate, indicate that the fertility in Croatia is not in such a bad position as it may appear. 


\section{References}

Akrap, A., Ridzak, T., Pokos, N., Živić, D., and Čipin, I. (2003). Činitelji demografskih kretanja u Republici Hrvatskoj: znanstveno-istraživački projekt (istraživanje činitelja fertiliteta u Hrvatskoj i mogućeg utjecaja nekih mjera obiteljske politike na odluku o broju djece). Zagreb: Državni zavod za zaštitu obitelji, materinstva i mladeži.

Becker, S., and Sidibe, N. (2001). Introduction to Demographic Methods: A multimedia CD-ROM course. Baltimore. (http://www.gatesinstitute.jhsph.edu/cddemo/demography)

Bongaarts, J. (1999). Fertility Decline in the Developed World: Where Will It End? The American Economic Review, 89(2), 256-260.

Bongaarts, J., and Feeney, G. (1998). On the quantum and tempo of fertility. Population and Development Review, 24, 271-292.

CBS. (1999). Statistical Yearbook of the Republic of Croatia 1999 (Tech. Rep.). Zagreb: Central Bureau of Statistic of the Republic of Croatia.

CBS. (2004). Statistical Yearbook of the Republic of Croatia 2004 (Tech. Rep.). Zagreb: Central Bureau of Statistic of the Republic of Croatia.

CEC. (2004). Recent Demographic Developments in Europe 2004 (Tech. Rep.). Strasbourg: Council of Europe.

Eurostat. (2005). Database (Tech. Rep.). Eurostat Brussels. (http://epp.eurostat.cec.eu.int)

Fernando, R. (2004). Soc 532 Demographic Models and Methods. London, Ontario: The University of Western Ontario - Faculty of Social Science.

Land, K. C., Yang, Y., and Yi, Z. (2005). Mathematical Demography. In D. L. Poston and M. Micklin (Eds.), Handbook of population (p. 659-717). New York: Kluwer Academic/Plenum.

Malačič, J. (2003). Demografija : teorija, analiza, metode in modeli (5. ed.). Ljubljana: Ekonomska Fakuleta.

Philipov, D., and Kohler, H. P. (2001). Tempo Effects in the Fertility Decline in Eastern Europe: Evidence form Bulgaria, the Czech Republic, Hungary, Poland, and Russia. European Journal of Population, 17(1), 37-60.

Preston, S. H., Heuveline, P., and Guillot, M. (2003). Demography: measuring and modeling population processes. Oxford: Blackwell Publiching.

Rowland, D. (2003). Demographic methods and concepts. New York: Oxford University Press.

Ryder, N. (1964). The Process of Demographic Translation. Demography, 1(1), 74-82.

Schoen, R. (2002). Mathematical Models in Demography and Actuarial Mathematics (Working Paper No. 02-07). University Park: Population Research Institute, The Pennsylvania State Univerity.

UN. (1997). Population by marital status, age, sex, and urban/rural residence, each census: 1948-1997 (Statstical data). New York: United Nations. (http://unstats.un.org/unsd/demographic/products/dyb/DYBHist/HistTab12.pdf)

UN. (1999). Live births by age of mother and live-birth or- 
der 1990-1998 (Tech. Rep.). New York: United Nations. (http://unstats.un.org/unsd/demographic/products/dyb/DYBNat/NatStatTab06.pdf) UN. (2003). Long-Range Population Projections (Tech. Rep.). New York: United Nations Population Division.

UN. (2004). World Population Prospects: The 2004 Revision (Tech. Rep.). New York: United Nations Population Division. (http://esa.un.org/unpp)

UN. (2005). Demographic Database of the Population Activities Unit (PAU-DB) (Tech. Rep.). Geneva: United Nations Economic Commission for Europe Population Activites Unit. (http://w3.unece.org/stat/pau.asp)

Wertheimer-Baletić, A. (1999). Stanovništvo i razvoj. Zagreb: Mate.

Xie, Y., and Pimentel, E. E. (1992). Age patterns of Marital Fertility: Revising the Coale-Trussell Method. Journal of the American Statistical Association, 87(420), 977-984.

Yi, Z., and Land, K. C. (2001). A sesitivity analysis of the Bongaarts-Feeney method for adjusting bias in observed period total fertility rates. Demography, 38(1), 17-28.

Author's address:

Ana Štambuk

School of Economics

University of Rijeka

Ivana Filipovica 4

51000 Rijeka

Croatia

Tel. +385 $51355-168$

Fax +385 51 212-268

E-mail: ana@efri.hr

http://www.efri.hr/djelatnici.asp?dj_id=34 